\title{
Assessment of ghrelin, GHS-R, GH, and neurohormones in human fetal pituitary glands and central nervous system: an immunohistochemical study
}

\author{
Andrzej Kedzia1, Monika Obara-Moszynska1, Maria Chmielnicka-Kopaczyk² \\ ${ }^{1}$ II Department of Pediatrics, Poznan University of Medical Sciences, Poznan, Poland \\ ${ }^{2}$ Department of Biochemistry and Pathology, Poznan University of Medical Sciences, Poznan, Poland
}

\begin{abstract}
The aim of this work was evaluation of expression of ghrelin and GHS-R1a receptor in somatotrops and in neuronal cells of brain tissue in the process of human fetal ontogenesis. Relations were also looked for between GHRH and SS in the pituitary and in the CNS neurones of the studied fetuses. The study was based on 8 pituitaries and 8 brains from fetuses in different periods of intrauterine life. The immunocytochemical technique was used. The presence of ghrelin, GHS-R was shown in the glandular part of the pituitary and CNS during the whole period of intrauterine life. Neurohormones in the stalk of the pituitary were found in fetuses from the 32nd week of pregnancy whereas in the CNS neurones these hormones could be detected throughout the whole period of intrauterine life. The results obtained suggest that stimulation of GH secretion by ghrelin is independent of the feedback concentration and these two hormones act like signals of metabolic balance. $\mathrm{GH}$ release by ghrelin in fetal life is independent of somatostatin. The hypothalamic-pituitary axis which regulates pulsatile $\mathrm{GH}$ release from the pituitary matures functionally in the thrid trimester of pregnancy independent of the previous anatomical differentiation.
\end{abstract}

Key words: ghrelin, GHS-R1a, GHRH, somatostatin, growth hormone, fetal pituitary glands, central nervous system, immunohistochemistry

\section{Introduction}

Ghrelin is the first natural hormone to be identified in which the serine residue in position 3 was estrified with n-octanoic acid. Various functions were attributed to this peptide, including the role in the release of growth hormone $(\mathrm{GH})$ from the pituitary gland and the control of the energeting homeostasis that regulates the energy usage by influencing the appetite - the pituitary intestine axis [1-3]. This function is mediated by the activation of the growth hormone secretagogue receptor (GHS-R) type 1a $[4,5]$. Ghrelin is produced predominantly by the stomach and the lower amount by other organs such as central nervous system (CNS) and peripheral tissue $[1,3,6]$. But several authors have questioned whether ghrelin expression really takes place in the central nervous system. Katakami et al.,

Correspondence: A. Kedzia, IInd Dept. of Pediatrics Poznan University of Medical Sciences, Division of Developmental Age Endocrinology and Diabetology, Szpitalna 27/33, 60-572 Poznan, Poland; tel.: (+4861) 8491425, fax.: (+4861) 8480291,

e-mail: akedzia@ump.edu.pl, hala6@o2.pl using real-time polymerase chain reaction, show undetectable levels in the cerebral cortex, or hypothalamus of the rhesus monkey [7]. Thus it cannot be ruled out that ghrelin in the hypothalamus may possibly derive from peripheri. However, Korbonits et al. detected ghrelin m-RNA message in the human and rat pituitary and hypothalamus using reverse transcriptase polymerase chain reaction $[6,8]$. In adult patients with isolated GH deficiency, ghrelin serum levels are similar to those of the control subject and do not decrease after one year of GH replacement therapy [9]. The presence of ghrelin was shown also in numerous peripheral organs during the intrauterine ontogenesis, however, the role ghrelin plays in the period of intrauterine life is not fully appreciated [10-12].

The aim of our study was to evaluate ghrelin expression and of its receptor (GHS-R1a) in somatotrops and in neurones of brain tissue of the III and IV ventricle in the process of fetal ontogenesis and evaluation of the probable role of these proteins in this period of life. It was checked whether there was a correlation between the degree of expression of ghrelin and GHS-R in somatotrops and CNS. In this study the 
Table 1. The list of studied fetuses according to the week of pregnancy, body mass, length of life

\begin{tabular}{|c|c|c|c|c|}
\hline$\#$ & $\begin{array}{c}\text { Histo- } \\
\text { pathology } \\
\text { number }\end{array}$ & $\begin{array}{c}\text { Week of } \\
\text { pregnancy }\end{array}$ & Body mass & $\begin{array}{c}\text { Lenght } \\
\text { of life } \\
\text { (hours) }\end{array}$ \\
\hline 1 & 188779 & 16 & 80 & - \\
\hline 2 & 8695 & 18 & - & - \\
\hline 3 & 8732 & 26 & 1540 & 7 \\
\hline 4 & 8733 & 27 & 910 & 18 \\
\hline 5 & 8742 & 30 & 2140 & 6 \\
\hline 6 & 8719 & 32 & 1320 & 96 \\
\hline 7 & 8721 & 35 & 2000 & 12 \\
\hline 8 & 8669 & 37 & 3115 & 15 \\
\hline
\end{tabular}

authors also looked for relations between GHRH (Growth Hormone Releasing Hormone) and SS (Somatostatine) in the pituitary and CNS neurones of the studied fetuses.

\section{Materials and methods}

Eight pituitaries and eight brains from different periods of intrauterine life were investigated. Organs for investigation were taken during autopsy after about 8 hours after death. The deceased newborns were kept in a refrigerator. Characterisation of the fetuses is presented in Table 1. The whole material was fixed in neutralised formalin; the pituitaries were fixed for 3-5 days, the brains for 2 weeks. Sections were taken from the area of the III and IV ventricle, were fixed again and then paraffin emboded. The pituitaries and brain material were cut serially, every $7^{\text {th }}$ section was stained with hematoxyline and eosin. Such a procedure allowed to choose proper tissue sections for immunohistochemical studies. Of the eight pituitaries studied in two, apart from the nervous and glandular part, the presence of infundibular stalk and of the tuberalis part was found. In five pituitaries the nervous and glandular parts were found while only in one pituitary the glandular part was found. In the nervous tissue five fragments came from the area of the III ventricle and in this case clusters of neurones localised in the vicinity of the bottom. In the other three fragments dispersed neurones were more often found, which were arranged in rows or "in indian file". The data on the antibodies used for the study are listed in Table 2.

Apart from antibodies used and listed in Table 2 in 1-5, there were also used a rabbit antibody against ghrelin and a mouse antibody against $\mathrm{GH}$ in order to perform double staining on the same section of the pituitary allowing to demonstrate both GH and ghrelin in somatotrops. As control material were used tissue sections from an adenoma of human pituitary positive for ghrelin and GH. Also a negative control was performed which consisted in omitting the first antibody. As a positive control of ghrelin and the receptor served sections of the pancreas from the 25 th week of pregnancy [10].

\section{Results}

A positive immunoreaction to the presence of ghrelin was found in the glandular portion and in brain tissue.

Pituitary: in the glandular part already of the youngest fetus from the $16^{\text {th }}$ week of pregnancy an immunopositive reaction was observed in dispersed or concentrated cells in small clusters. Staining in the area of the cell was localised in the cytoplasm, nuclei were not stained. The number of immunopositive cells increased as the pregnancy advanced until the $30^{\text {th }}-35^{\text {th }}$ week. They were distributed in the peripheral glandular part of the pituitary, were concentrated nests and were found in the area of the $3 / 4$ of the glandular structures. In the remaining $1 / 4$ of this part no positive reaction was observed (10). In the period between the $35^{\text {th }}$ and $37^{\text {th }}$ week of pregnancy the picture of distribution of ghrelin-positive cells did not show any significant differences as compared to the $30^{\text {th }}-35^{\text {th }}$ week of pregnancy. The degree of ghrelin expression was high and similar during the whole period of intrauterine life of the fetuses studied. In the nerves pituitary part the cells were not stained.

Brain tissue: in the youngest fetuses single ghrelinpositive cells occurred. As the age of fetuses advanced the number of positive neurones was increasing in the

Table 2. The list of antibodies used, manufacturers, dilution and the techniques

\begin{tabular}{|c|c|c|c|c|}
\hline \# & Antibodies & Manufacturer & Dilution & Techniques \\
\hline 1 & Anti-ghrelin & $\begin{array}{l}\text { Santa Cruz. } \\
\text { Biotechnology, Inc. }\end{array}$ & $1: 150$ & \multirow{5}{*}{ LSAB $\mid$ System HRP } \\
\hline 2 & Anti-GHS-R1 & $\begin{array}{l}\text { Santa Cruz } \\
\text { Biotechnology, Inc. }\end{array}$ & $1: 20$ & \\
\hline 3 & Anti-GH & Dako Poland Sp. zo.o. & Ready to use & \\
\hline 4 & Anti-GHRH & $\begin{array}{l}\text { Santa Cruz } \\
\text { Biotechnology, Inc. }\end{array}$ & $1: 50$ & \\
\hline 5 & Anti-somatostatin & Dako Poland Sp. z o.o. & Ready to use & \\
\hline 6 & Rabbit anti-ghrelin (human) serum & $\begin{array}{l}\text { Phoenix } \\
\text { Pharmaceuticals, Inc. }\end{array}$ & $1: 800$ & \multirow{2}{*}{$\begin{array}{l}\text { EnVision Doublestain } \\
\text { System }\end{array}$} \\
\hline 7 & $\begin{array}{l}\text { Monoclonal anti-growth hormone } \\
\text { antibody produced in mousc }\end{array}$ & Sigma & $1: 200$ & \\
\hline
\end{tabular}



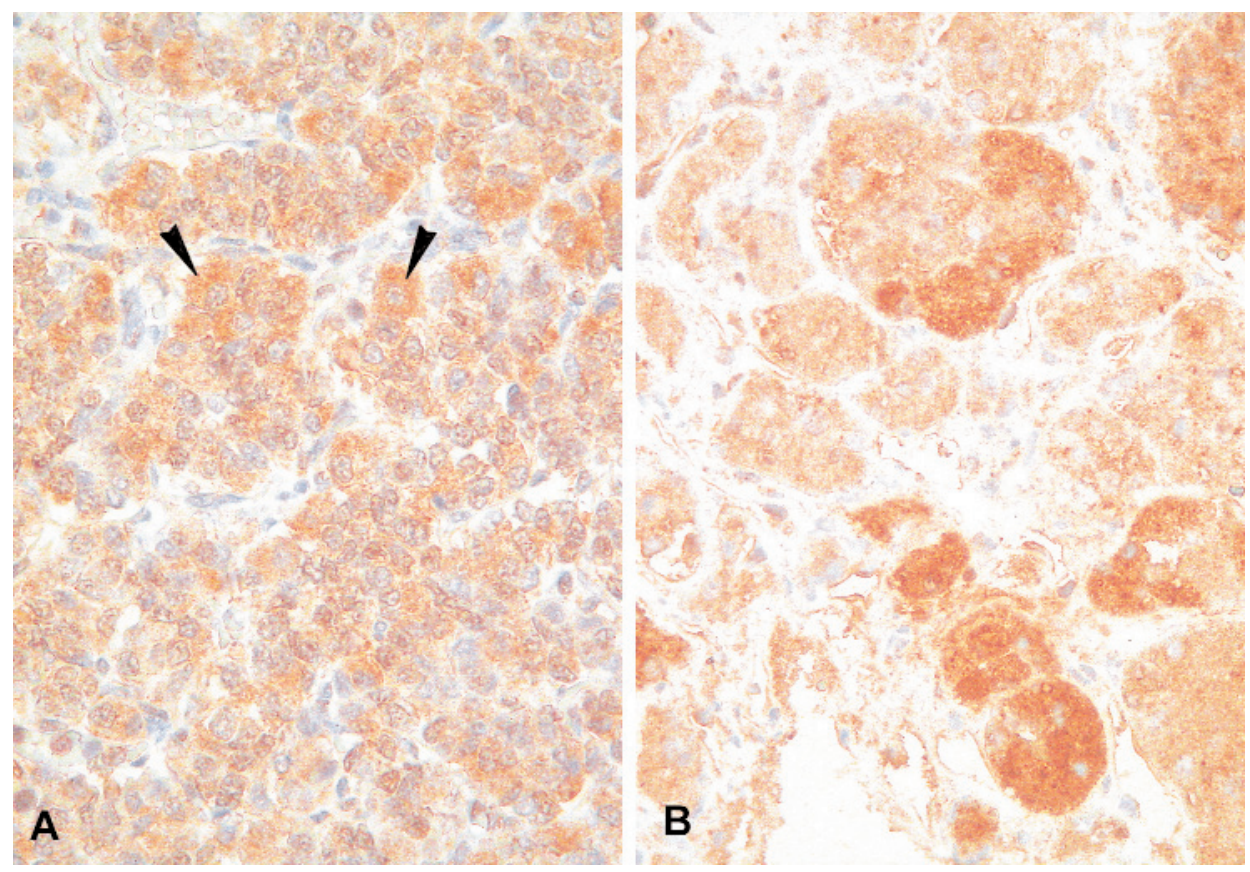

Fig. 1. A two-colour reaction marking somatotrops synthesising both $\mathrm{GH}$ and ghrelin - cherry-russet staining. (A) The pituitary of a fetus from the $33^{\text {rd }}$ week of intrauterine life. Somatotrops showing both hormones are marked with arrows. (B) Adenoma of human pituitary. The cherry-russet staining marks cells which synthesise both the studied hormones. Hematoxylin counterstain (original magnification $\times 300$ ). area of the III ventricle, but the intensity of staining was moderate and significantly weaker when compared with somatotrops.

\section{GHS-R1a}

Localisation a receptor in the glandular part of the pituitary and in brain tissue was similar to that of ghrelin. Expression of immunoreaction in the glandular part of the pituitary was similar to that of ghrelin whereas in the neurones of brain tissue it was definitely stronger as compared to the immunoreaction to ghrelin. Localisation of the immunopositive reaction to the presence of GHS-R1a concerned cell membrane and cytoplasm.

\section{Growth hormone}

Positive immunoreaction to GH was observed only in the glandular part of the pituitary. Already in the pituitaries of the youngest fetuses $\left(16^{\text {th }}-18^{\text {th }}\right.$ week) immunopositive somatotrops were collected in large clusters. Staining reaction was localised in the cytoplasm and the nuclei were negative. In older fetuses of up to $33^{\text {rd }}-35^{\text {th }}$ week of pregnancy the number of growth hormone-rich cells was increasing. They were located mainly in the peripheral part of the pituitary. The degree of immunoreaction expression was intensive throughout the whole intrauterine life of fetuses. In the negative field of the glandular portion in the staining for ghrelin and GHS-R no presence of GH was shown either.

In the double staining reaction identifying somatotrops synthesising both ghrelin and GH were stained cherry-russet (Fig. 1a). A similar picture was obtained on the tissue sections, coming from the adenoma of a human pituitary (Fig. 1b). In the somatotrops of the fetal pituitary the immunoreaction demonstrating these two hormones was more homogeneous while in the adenoma it was stronger.

\section{Neurohormones}

Pituitary: of the 8 investigated pituitaries only in two a infundibular stalk and tuberalis were found. They came from the $32^{\text {nd }}$ and $35^{\text {th }}$ weeks of the intrauterine life. In the stalk a positive immunoreaction was observed to the presence of GHRH and SS in the form of a fibrous delicate network forming delicate grains on a fibrous background (Fig. 2). In the nervous and tuberalis part and in the glandular part positive reaction to both studied hormones was not observed.

Brain tissue: reaction to GHRH and somatostatin in the material from the area of the III and IV ventricle was observed in single neurones and in nests localised in the area of the forming cerebral cortex (Fig. 3). Within the III ventricle neurones were observed which were arranged "in indian file". As the intrauterine age was growing the number of positive neurones was increasing up to the $32^{\text {nd }}-36^{\text {th }}$ weeks of pregnancy. A positive reaction was observed in the neuroplasm and in the appendages cell. The degree of expression was different.

\section{Discussion}

The endogenic ghrelin induces GH secretion in the pituitary somatotrops in man and in adult animals $[3,12,13]$. Thus, it exerts a similar influence on soma- 

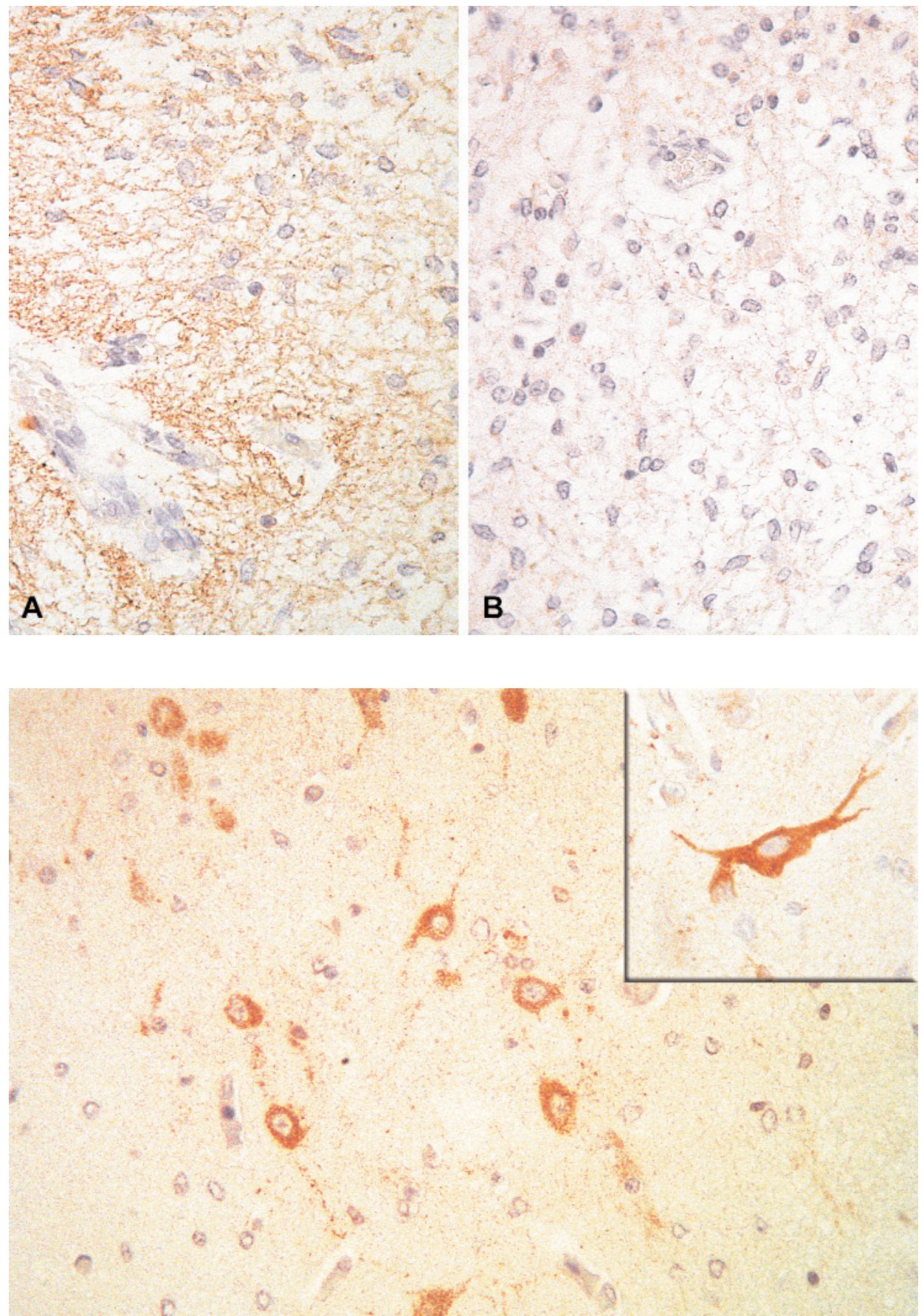

Fig. 2. (A) Positive reaction to GHRH in the form of a delicate brown net in the pedicle of a fetus coming from the 33-weeks old pregnancy. (B) Negative control. Hematoxylin counterstain (original magnification $\times 300$ ).

Fig. 3. Positive reaction to the presence of GHRH and SS in the neurones of the III ventricle surrounding of the brain. In the inset can be seen a reaction to GHRH in the cytoplasm and appendages of a single neuronal cell. In the other neurones can be seen a positive immunoreaction to somatostatin. Hematoxylin counterstain (original magnification $\times 400$ and $\times 300$ ).

totrops as a whole group of non-peptide and peptide growth hormone secretagogues - GHS which have been discovered during the recent three decades $[3,14,15]$. The intravenously administered ghrelin induces during 15-20 minutes a maximal GH concentration in blood serum, and administered continually apart from GH secretion also induces growth of appetite, fat accumulation, increase in acid secretion and greater mobility of the stomach $[1,6,16,17]$. So ghrelin, apart from the somatotropin system also takes part in the brain-intestine axis [14]. The participation of ghrelin in the brain-intestine axis may also be traced in the intrauterine life of the fetuses. According to some researchers glucose deficiency connected with malnutrition of pregnant women, increases ghrelin concentration in the serum of umbilical blood of newborns. It was shown in clinical observations and in an experiment performed on laboratory animals $[18,19]$. In this field ghrelin acts with leptin forming a complementary regulating system which informs CNS about the energetic condition of the organism. The mechanism of ghrelin influence on somatotrops takes place 
by the mediation of a receptor (GHS-R) which belongs to a family of seven transepithelial receptor of the $G$ protein. This receptor is found mostly in the pituitary, nuclei of the hypothalamus and, to a lesser degree in the peripheral tissues [8]. The mechanism of ghrelin activity in GH release from the pituitary has not been fully recognised. Kineman and Luque studied the mechanism of ghrelin and GHRH influence on GH release in the culture of somatotrops of an adult baboon [13]. There studies showed that the intracellular signal pathway of both these hormones are different and increase GH secretion depending on the receptor regulation. Mice deprived of the GHS-R gene lose weight, ghrelin does not release GH secretion in the pituitary and their organism is not capable of maintaining an appropriate glucose level during starvation and caloric restriction [20]. Rindi et al. emphasise, on the basis of a survey of literature on the subject, that the function of ghrelin in adults is not regulated by GH through the classic feedback mechanism while studies of ghrelin in the pituitary of human fetuses are exceptionally scarce and this problem was dealt with only when ghrelin expression in the endocrine tumors of the pituitary was evaluated $[6,8,11,12]$. In our study we showed an immunopositive reaction to ghrelin in somatotrops and in neurones concentrated mainly in the area of the III ventricle of the brain already in the youngest fetuses of $16^{\text {th }}-18^{\text {th }}$ weeks. Ghrelin expression was also accompanied by high GH activity in somatotrops. GH presence in the somatotrops of the human pituitary was shown as early as the $7^{\text {th }}-10^{\text {th }}$ week of fetal life [12,21]. We showed that the significantly higher ghrelin expression in somatotrops compared with its presence in neurones may suggest a great involvement of this hormone in the control of GH synthesis in somatotrops. Whereas ghrelin expression in neurones was very moderate and its role in the stimulation of GH secretion in somatotrops is unclear and so far has not been fully explained. Of interest is our observation pointing to a relatively high GHS-R expression in neuronal cells with a slight ghrelin expression. This phenomenon is difficult to explain at present. It can only be suggested that the activity of ghrelin receptor may be independent on the GHRH receptor. According to some researchers the hypothalamus in human fetuses is differentiated into separate nuclei as early as in the $12^{\text {th }}$ week of intrauterine life [22]. The concentrations of neurones which we have observed may be the proof of a longer phase of formation of the hypothalamus nuclei and this fact may be confirmed by the groups of neurones migrating "one after another" to their destinations. In the neurones described we have found an immunopositive reaction to somatostatin and GHRH. In the stalk of two pituitaries from the $32^{\text {nd }}-35^{\text {th }}$ weeks of pregnancy we showed an immunopositive reaction both to somato- statin and GHRH. In the pituitary of younger fetuses we have not observed these neurohormones [11]. Bresson et al. did not discover the presence of GHRH in the brain until the $18^{\text {th }}$ week of pregnancy while Aubert et al. showed that there was somatostatin in the cortex and hypothalamus already from the $11^{\text {th }}$ week of pregnancy and expression of this hormone was increasing until the $22^{\text {nd }}$ week of pregnancy $[23,24]$. Furuhashi et al. determined GH and SS concentration in the serum of umbilical blood in newborns and their mothers, and showed a more than four times higher GH concentration in the blood serum of fetuses than in their mothers while the SS concentration was similar in mothers and fetuses [25]. In the blood serum of mothers in the third trimester of pregnancy GH comes mainly from the placenta and so far there has been no proof of its transmission to fetal circulation [26]. On the other hand, it is assumed that $\mathrm{GH}$ in fetal circulation comes chiefly from the fetal pituitary. It is curious that the concentration of the placental GH in the blood serum of the mother is correlated with the weight of the fetus while ghrelin concentration in the serum of umbilical blood of fetuses is not correlated with body mass index (BMI), time of pregnancy, length of the fetus, and circumference of the head [27]. Our knowledge of the fetal ghrelin is still limited, particularly when mechanisms controlling GH production in fetal life are concerned. Most authors emphasise that in fetal life GH release by ghrelin from the pituitary is independent of somatostatin corticostatin $[12,14]$. Our studies confirm this suggestion. As the age of a fetus advanced the number of neurones which synthesise both neurohormones was increasing, this may suggest that also their concentration in blood serum of the fetuses was growing in proportion to age.

To sum up, we can suggest that the stimulation of $\mathrm{GH}$ secretion by ghrelin is independent of the feedback concentration and these two hormones act as signals of metabolic balance. GH release by ghrelin in fetal life is independent of somatostatin. The hypothalamicpituitary axis which regulates the pulsatile GH release from the pituitary matures functionally probably in the third trimester of pregnancy independent of the previous anatomical differentiation.

\section{References}

[ 1] Kojima M, Hosoda H, Date Y, Nakazato M, Matsuo H, Kangawa $\mathrm{K}$. Ghrelin is a growth-hormone-releasing acylated peptide from stomach. Nature. 1999;402:656-660.

[2] Peino R, Baldelli R, Rodriguez-Garcia J et al. Ghrelininduced growth hormone secretion in humans. Eur $J$ Endocrinol. 2000; 143:R11-R14.

[3] Kędzia A, Przbyszewska W. Ghrelin - a new hormone involved in growth regulation and metabolic homeostasis of the organism. Endocrin Pediat. 2007;9:53-60.

[4] Howard AD, Feighner SD, Cully DF et al. A receptor in pituitary and hypothalamus that functions in growth hormone release. Science. 1996;273:974-977. 
[ 5] van der Lely AJ, Tschöp M, Heiman ML, Ghigo E. Biological, physiological, pathophysiological, and pharmacological aspects of ghrelin. Endocr Rev. 2004;25:426-457.

[6] Korbonits M, Kojima M, Kangawa K, Grossman AB. Presence of ghrelin in normal and adenomatous human pituitary. Endocrine. 2001;14:101-104.

[7] Katakami H, Shimizu K, Kimura N, Ashida S, Terasawa E. Cloning and characterization of ghrelin and GHRH in the rhesus monkey, Macaca mulatta OR-47-2. In: Proceedings of the Endocrine Society $86^{\text {th }}$ Annual Meeting. New Orleans, USA. June 16-19, 2004.

[ 8] Korbonits M, Bustin SA, Kojima M et al. The expression of the growth hormone secretagogue receptor ligand ghrelin in normal and abnormal human pituitary and other neuroendocrine tumors. J Clin Endocrinol Metab. 2001;86:881-887.

[9] Janssen JA, van der Toorn FM, Hofland LJ et al. Systemic ghrelin levels in subjects with growth hormone deficiency are not modified by one year of growth hormone replacement therapy. Eur J Endocrinol. 2001;145:711-716.

[10] Kędzia A, Chmielnicka-Kopaczyk M, Uklejewska D, ObaraMoszyńska M. Immunohistochemical assessment of ghrelin expression and recptor (GHS-R) in human fetal organs. Arch Parinat Med. 2006;12:12-16.

[11] Kędzia A, Obara-Moszyńska M, Chmielnicka-Kopaczyk M. Immunohistochemical assessment of ghrelin, GHS-R, GH, GHRH and somatostatin in pituitary glands of human fetuses. Arch Perinat Med. 2007;13:44-48.

[12] Rindi G, Torsello A, Locatelli V, Solcia E. Ghrelin expression and actions; a novel peptide for an old cell type of the diffuse endocrine system. Exp Biol Med. 2004;229:1007-1016.

[13] Kineman RD, Luque RM. Evidence that ghrelin is as potent as growth hormone $(\mathrm{GH})$-releasing hormone $(\mathrm{GHRH})$ in releasing $\mathrm{GH}$ from primary pituitary cell cultures of a nonhuman primate (Papio anubis), acting through intracellular signaling pathways distinct from GHRH. Endocrinology. 2007; 148:4440-4449.

[14] Ghigo E, Broglio F, Arvat E, Maccario M, Papotti M, Muccioli G: Ghrelin: more than a natural GH secretagogue and/or an orexigenic factor. Clin Endocrinol (Oxf). 2005;62:1-17.

[15] Locatelli V, Grilli R, Torsello A, Cella SG, Wehrenberg WB, Müller EE. Growth hormone-releasing hexapeptide is a potent stimulator of growth hormone gene expression and release in the growth hormone-releasing hormone-deprived infant rat. Pediatr Res. 1994;36:169-174.

[16] Tschöp M, Smiley DL, Heiman ML. Ghrelin induces adiposity in rodents. Nature. 2000;407:908-913.

[17] Masuda Y, Tanaka T, Inomata N et al. Ghrelin stimulates gastric acid secretion and motility in rats. Biochem Biophys Res Commun. 2000;276:905-908.

[18] Wang X, Liang L, Du L. The effects of intrauterine undernutrition on pancreas ghrelin and insulin expression in neonate rats. J Endocrinol. 2007;194:121-129.

[19] Farquhar J, Heiman M, Wong AC, Wach R, Chessex P, Chanoine JP. Elevated umbilical cord ghrelin concentrations in small for gestational age neonates. $J$ Clin Endocrinol Metab. 2003;88:4324-4327.

[20] Sun Y, Asnicar M, Taftet G, Smith RG. Phenotype of ghrelin receptor knockout mite. In: Proceedings of the Endocrine Society $86^{\text {th }}$ Annual Meeting. New Orleans, USA. June 1619, 2004.

[21] Matsuzaki F, Irie M, Shizume K. Growth hormone in human fetal pituitary glands and cord blood. J Clin Endocrinol Metab.1971;33:908-911.

[22] Hyyppä M. Hypothalamic monoamines in human fetuses. Neuroendocrinology. 1972;9:257-266.

[23] Bresson JL, Clavequin MC, Fellmann D, Bugnon C. Ontogeny of the neuroglandular system revealed with HPGRF 44 antibodies in human hypothalamus. Neuroendocrinology. 1984;39:68-73.

[24] Aubert ML, Grumbach MM, Kaplan SL. The ontogenesis of human fetal hormones. IV. Somatostatin, luteinizing hormone releasing factor, and thyrotropin releasing factor in hypothalamus and cerebral cortex of human fetuses 10-22 weeks of age. J Clin Endocrinol Metab. 1977;44:1130-1141.

[25] Furuhashi N, Takahashi T, Fukaya T et al. Plasma somatostatin and growth hormone in the human fetus and its mother at delivery. Gynecol Obstet Invest. 1983;16:59-62.

[26] Fuglsang J, Ovesen P. Aspects of placental growth hormone physiology. Growth Horm IGF Res. 2006;16:67-85.

[27] Pirazzoli P, Lanari M, Zucchini S. Active and total ghrelin concentrations in the newborn. $J$ Pediatr Endocrinol Metab. 2005;18:379-384.

Submitted: 28 September, 2008 Accepted after reviews: 6 June, 2009 